УДК 330.1

DOI: $10.14451 / 1.188 .18$

ГРНТИ 06.52.13

\title{
ТЕХНОЛОГИЧЕСКАЯ ТРАНСФОРМАЦИЯ И «РИКАРДИАНСКИЙ ЭФФЕКТ»: УГРОЗЫ ДЛЯ ЭКОНОМИЧЕСКОГО РАЗВИТИЯ И ПУТИ ИХ ПРЕОДОЛЕНИЯ
}

\author{
(C) 2020 Лихачев Михаил Олегович \\ доктор экономических наук, доцент, профессор кафедры Экономической теории и менеджмента \\ Московский педагогический государственный университет, Россия, Москва \\ E-mail:olegmix71@mail.ru
}

В статье рассматриваются общие закономерности технологических трансформаций в рыночной экономике и их отражение в теоретических концепция классической политической экономии и, в частности, в теории Д. Рикардо. Описывается и рассматривается модель «рикардианского эффекта», который заключается в том, что лидирующий в технологическом отношении сектор экономики может подвергнуться стагнации из-за слишком высокого уровня внутренней конкурентности и чрезмерной сырьевой зависимости от технологических отсталых секторов экономики, что приведет к торможению экономического роста во всей экономике в целом.

Ключевые слова: технологическая трансформация, экономический рост, межсекторные диспропорции, «рикардианский эффект», закон убывающего плодородия, закон понижения нормы прибыли, стагнация

Современная рыночная экономика сформировалась в результате целого ряда технологических трансформаций, начиная с «индустриальной революции» конца XVIII - начала XIX вв. и заканчивая современной «цифровой революцией» на рубеже XX-XXI вв. Общей чертой всех этих технологических трансформаций было возникновение межсекторных диспропорций, меняющих структуру экономической системы и оказывающих влияние на долгосрочное экономическое развитие. Процесс технологических изменений, как правило, является неравномерным и в наибольшей степени затрагивает один из секторов экономики, создавая определенную напряженность в ее отношениях с другими секторами. Эта напряженность может создавать препятствия на пути начавшейся технологической трансформации и даже угрожать ввергнуть трансформирующуюся экономическую систему в кризисное состояние. Эта парадоксальная тенденция проявилась еще в период первой «индустриальной революции» и нашла свое отражение в трудах экономистов того времени и, в первую очередь, представителей классической политической экономии $[1 ; 4 ; 6 ; 8]$. В тот период межсекторная диспропорция возникала как результат бурного технологического развития в промышленности в сочетании с сохраняющимися существенными ограничениями производственных возможностей в аграрном секторе.
Первым экономистом-классиком, в работах которого можно обнаружить анализ проблем, вызванных бурным развитием промышленности и ограниченностью природных и технологических ресурсов сельского хозяйства, несомненно, является Д.Рикардо. В теории Д. Рикардо проблема разрыва в развитии промышленности и сельского хозяйства предстает как взаимодействие двух тенденций: растущей (вследствие роста городского населения) потребности общества в продовольствии и убывающего плодородия земли, приводящего к росту его стоимости.

Убывание плодородия почв ведет к повышению затрат необходимых для производства продовольствия. Но, поскольку, с ростом населения спрос на продовольствие растет, земля, которая является необходимым фактором для его производства, не может быть замещена в производственном процессе другими, более производительными факторами. Наоборот, объем ее применения возрастает. В производство вовлекаются все более худшие земли. Превращение земли - наименее производительного ресурса, в дефицитный ресурс подрывает динамическую эффективность экономики. Форсированное использование менее производительных ресурсов неизбежно отражается на формировании всех пропорций экономической системы.

Этот процесс, естественно, отражается на пропорции распределения: доля дохода земель- 
ных собственников (рента) возрастет за счет снижения доли дохода собственников капитала (прибыли). Это перераспределение происходит за счет роста стоимости рабочей силы, который выражается в росте номинальной заработной платы: продукты питания составляют большую часть потребления рабочих, поэтому рост цен на продовольствие, вызываемый снижением плодородия почв, должен компенсироваться соответствующим ростом заработной платы. Если при этом цены на промышленную продукцию остаются неизменными или снижаются, то рост издержек на заработную плату оборачивается снижением прибыли и предприниматель «... вместо того, чтобы постоянно получать большую прибыль, окажется вынужденным довольствоваться меньшей нормой ее как неизбежным последствием повышения заработной платы, вызванного повышением цен на предметы насущной необходимости» [5, с. 106]. Так происходит перераспределение общественного дохода в пользу земельной ренты.

Поскольку процесс убывания плодородия земли в ходе экономического развития не прекращается «...прибыль имеет естественную тенденцию падать...» [5, с. 106] и перераспределение дохода от капиталистов к земледельцам продолжается. Оно будет продолжаться до тех пор, пока пропорция распределения не будет деформирована настолько, что исчезнет всякий стимул для дальнейшего экономического развития, то есть «...весьма низкая норма прибыли остановит всякое накопление, и почти весь продукт страны, за вычетом платы рабочим, станет собственностью землевладельцев...» [5, с. 106]

При этом Д.Рикардо выделяет ряд факторов, противодействующих общей тенденции падения прибыли. Он полагает, что «...эта тенденция... приостанавливается через повторные промежутки времени благодаря усовершенствованиям в машинах, применяемых в производстве предметов жизненной необходимости, а также открытиям в агрономической науке, которые позволяют нам сберечь часть труда, требовавшегося раньше и таким образом понизить цену предметов первой необходимости рабочего» $[5$, с. 106].

Таким образом теория Д.Рикардо предполагает, что технологически более передовой промышленный сектор проигрывает отсталому аграрному сектору во-первых, в силу более высокой внутренней конкурентности, приводящей к падению прибылей в промышленности вслед- ствие снижения цен и, во-вторых, в силу сырьевой зависимости от агарного сектора, который сталкиваясь с ресурсными ограничениями увеличивает себестоимость и цены своей продукции, одновременно увеличивая издержки для промышленности. Это явление можно назвать «рикардианским эффектом», который, если определить его в более общем виде, будет заключаться в том, что лидирующий в технологическом отношении сектор экономики, создавая повышенный спрос на сырье производимое отсталыми секторами, испытывает давление присущих им ресурсных ограничений, выражающегося в росте издержек производства, которые он не может компенсировать повышением цен в силу более высокого уровня конкурентности на своем рынке. Быстрое технологическое развитие и более высокая конкуренция становятся «ахиллесовой пятой» лидирующего технологического сектора, обрекая его на быструю потерю инвестиционной привлекательности.

\section{Трехсекторная рикардианская модель}

Долгосрочную рикардианскую модель можно представить как трехсекторную экономику, включающую в себя сектор сельскохозяйственного производства, сектор капитальных и сектор потребительских товаров. Совокупный объем национального производства в такой системе можно представить как сумму объемов производства трех секторов при соответствующих средних уровнях цен по секторам:

$$
Y p=Y_{1} p_{1}+Y_{2} p_{2}+Y_{3} p_{3}
$$

Где $\mathrm{Y}_{1}, \mathrm{Y}_{2}, \mathrm{Y}_{3}$ - реальные объемы производства, соответственно в сельскохозяйственном секторе, секторе производства капитальных товаров и секторе предметов потребления, a $\mathrm{p}_{1}$, $\mathrm{p}_{2}, \mathrm{p}_{3}$ - средние уровни цен, соответственно, в сельскохозяйственном секторе, секторе капитальных и секторе потребительских товаров.

Для каждого сектора будет характерна своя производственная функция. В сельскохозяйственном секторе она будет характеризоваться убывающей отдачей, а для секторов капитальных и потребительских товаров характерны линейные производственные функции с постоянной отдачей:

$$
\begin{aligned}
& \mathrm{Y}_{1}=f\left(\mathrm{~N}_{1}\right), f^{\prime}\left(\mathrm{N}_{1}\right)>0, f^{\prime \prime}\left(\mathrm{N}_{1}\right)<0 \\
& \mathrm{Y}_{2}=\mathrm{bN}_{2} \\
& \mathrm{Y}_{3}=\mathrm{cN}_{3}
\end{aligned}
$$


Заработная плата наемных работников может быть определена как стоимость минимального потребительского набора, включающего в себя продукцию первого и третьего сектора, то есть сельскохозяйственные продукты и предметы потребления:

$$
\mathrm{w}=\mathrm{y}_{1} \mathrm{p}_{1}+\mathrm{y}_{3} \mathrm{p}_{3}
$$

где $\mathrm{y}_{1}$ и $\mathrm{y}_{3}-$ количества, соответственно, сельскохозяйственных продуктов и предметов потребления промышленного производства, входящих в минимальный потребительский набор, составляющий реальную заработную плату работников.

Исходя из этого можно построить систему уравнений, описывающую формирование уровней цен по секторам экономической системы:

$$
\begin{aligned}
& \left(\frac{N_{1}}{Y_{1}}\left(y_{1} p_{1}+y_{3} p_{3}\right)+\frac{a K_{1} p_{2}}{Y_{1}}\right)\left(1+p^{\prime}\right)=p_{1} \\
& \left(\frac{N_{2}}{Y_{2}}\left(y_{1} p_{1}+y_{3} p_{3}\right)+\frac{a K_{2} p_{2}}{Y_{2}}\right)\left(1+p^{\prime}\right)=p_{2} \\
& \left(\frac{N_{3}}{Y_{3}}\left(y_{1} p_{1}+y_{3} p_{3}\right)+\frac{a K_{3} p_{2}}{Y_{3}}\right)\left(1+p^{\prime}\right)=p_{3}
\end{aligned}
$$

Где а - коэффициент, отражающий долю амортизации, а $\mathrm{K}_{1}, \mathrm{~K}_{2}, \mathrm{~K}_{3}$ - объемы капитала, функционирующего, соответственно, в секторе сельскохозяйственного производства и в секторах, производящих капитальные и потребительские товары. Эта система предполагает одновременное определение всех цен друг через друга. Решение системы может быть получено в результате итеративного процесса, исходной точкой которого может послужить любой случайный набор цен [3; 7]. В краткосрочном периоде система неизбежно придет к значениям цен, удовлетворяющим условиям данной системы. Однако в долгосрочной перспективе параметры системы не могут оставаться неизменными. В первую очередь это касается параметра $\mathrm{N}_{1} / \mathrm{Y}_{1}$, отражающего трудоемкость сельскохозяйственного производства, которая в долгосрочной перспективе имеет тенденцию возрастать. Этот рост неразрывно связан со снижением предельной производительности труда в сельском хозяйстве вследствие убывания плодородия земли.

Учитывая заданные свойства производственной функции в секторе производящем сельскохозяйственные продукты, изменение трудоемкости сельскохозяйственного производства можно выразить как:

$$
d \frac{N_{1}}{Y_{1}}=\frac{1}{f\left(N_{1}\right)}
$$

Поскольку $f^{\prime \prime}\left(\mathrm{N}_{1}\right)<0$, трудоемкость сельскохозяйственного производства возрастает вместе с ростом численности работников, используемых в сельскохозяйственном производстве.

Увеличение трудоемкости сельскохозяйственного производства ведет к увеличению цен на продукцию сельского хозяйства и росту номинальной заработной платы. Однако, согласно теории относительных цен, разработанной Д.Рикардо, на цены товаров непосредственно влияют только изменения трудозатрат на производство этих товаров, но не изменение стоимости труда, выражающееся в изменении номинальной заработной платы. Ведь изменение номинальной заработной платы изменяет стоимость всех товаров, в том числе и денежного товара, на одинаковую величину. На сколько дорожают товары, на столько же дорожают и деньги. Поэтому их относительные цены, выраженные в денежном измерении, остаются неизменными. Ценность денег в этом случае также остается неизменной, а возросшая номинальная заработная плата уравновешивается снижением нормы прибыли. Это необходимо учитывать при рассмотрении эффекта, производимого увеличением трудоемкости сельскохозяйственного производства.

Изменение уровня цен сельскохозяйственной продукции, вызванное повышением, ее трудоемкости можно представить как:

$$
\begin{aligned}
& \left(1+p^{\prime}\right)\left(y_{1} p_{1}+y_{3} p_{3}\right) \frac{1}{f\left(N_{1}\right)}+\left(1+p^{\prime}\right) \frac{N_{1}}{Y_{1}} y_{1} d p_{1}+ \\
& +\left(\frac{N_{1}}{Y_{1}}\left(y_{1} p_{1}+y_{3} p_{3}\right)+\frac{a K_{1} p_{2}}{Y_{1}}\right) d p^{`}=d_{1}
\end{aligned}
$$

Однако, поскольку на уровень цен влияет только изменение трудозатрат, но не изменение стоимости труда, изменение уровня цен на сельхозпродукцию можно записать как:

$$
\left(1+p^{\prime}\right)\left(y_{1} p_{1}+y_{3} p_{3}\right) \frac{1}{f^{\prime}\left(N_{1}\right)}=d p_{1}
$$

при

$$
\left(1+p^{\prime}\right) \frac{N_{1}}{Y_{1}} y_{1} d p_{1}+\left(\frac{N_{1}}{Y_{1}}\left(y_{1} p_{1}+y_{3} p_{3}\right)+\frac{a K_{1} p_{2}}{Y_{1}}\right) d p^{`}=0 ;
$$


Отсюда изменение нормы прибыли, необходимое для уравновешивания изменения стоимости труда можно представить как:

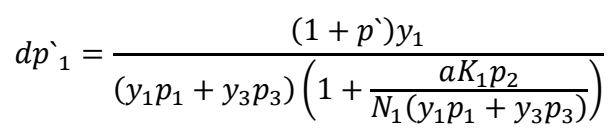

Изменение стоимости труда неизбежно отразится на норме прибыли в секторах производящих капитальные и потребительские товары. Эти изменения можно выразить как:

$$
\begin{aligned}
& d p_{1}^{\prime}=\frac{\left(1+p^{\prime}\right) y_{1}}{\left(y_{1} p_{1}+y_{3} p_{3}\right)\left(1+\frac{a K_{2} p_{2}}{N_{2}\left(y_{1} p_{1}+y_{3} p_{3}\right)}\right)} \\
& d p_{1}^{\prime}=\frac{\left(1+p^{\prime}\right) y_{1}}{\left(y_{1} p_{1}+y_{3} p_{3}\right)\left(1+\frac{a K_{3} p_{2}}{N_{3}\left(y_{1} p_{1}+y_{3} p_{3}\right)}\right)}
\end{aligned}
$$

Очевидно, что изменения нормы прибыли по секторам будут неодинаковы. Эти различия обусловлены различием уровня капиталовооруженности труда $(\mathrm{K} / \mathrm{N})$ между секторами. Чем выше будет уровень капиталовооруженности, тем меньше будет снижение нормы прибыли. Если предположить, что самая высокая капиталовооруженность труда существует в секторе, производящем капитальные товары, а самая низкая в сельскохозяйственном производстве, то в результате повышения трудоемкости сельскохозяйственного производства, норма прибыли в производстве капитальных товаров станет выше нормы прибыли предпринимателей, работающих в сельском хозяйстве [11]. Разумеется, межотраслевая конкуренция через какое-то время нивелирует эти различия, изменив относительные цены товаров. Относительная цена капитальных товаров понизится вследствие увеличения капиталовложений и роста объемов производства, а относительные цены сельскохозяйственных продуктов повысятся вследствие ограничения приложения капитала к земле. Именно это подразумевал Д.Рикардо, утверждая, что «...степень изменения относительной стоимости товаров вследствие повышения или падения стоимости труда будет зависеть от того, какую долю всего затраченного капитала составляет основной капитал. Упадет относительная стоимость всех товаров, в производстве которых применяются очень дорогие машины или очень дорогие здания... тогда как относительная стоимость тех товаров, которые производятся главным образом трудом... повысится» [5, с. 426].

Возможности смягчения «рикардианского эффекта»

Долгосрочная рикардианская модель предполагает непрерывное нарастание межсекторных диспропорций. Рост спроса на продовольствие, вызванный ростом населения с фатальной неизбежностью, вызывает снижение плодородия земли и увеличение цен на сельскохозяйственную продукции и, как следствие всего этого, снижение нормы прибыли. Однако если учесть в этой модели противодействующие тенденции, то можно сформулировать условия долгосрочного равновесия, которое обеспечит стабильность отношений между секторами экономики. Д. Рикардо выделяет в качестве противодействующих тенденций усовершенствования агрономической техники и усовершенствование машин, производящих предметы жизненной необходимости. Эту классификацию нельзя признать достаточно строгой поскольку усовершенствование в технике земледелия может выражаться в создании новых сельскохозяйственных машин, сокращающих капитальные затраты на единицу продукции. А это одновременно будет означать усовершенствование машин, производящих предметы жизненной необходимости.

Более четко можно выделить четыре причины, противодействующие закону убывания плодородия земли и снижению средней нормы прибыли:

1) Внедрение в сельскохозяйственном производстве трудосберегающих технологий, позволяющих компенсировать естественное снижение плодородия земли, не увеличивая при этом затрат капитала на единицу продукции. В этом случае трудоемкость сельскохозяйственного производства будет оставаться неизменной

$$
\left(d \frac{N_{1}}{Y_{1}}=0\right)
$$

и вся система цен, и норма прибыли будет оставаться неизменной в течение неопределенно долгого периода времени.

2) Внедрение капиталосберегающих технологий в сельскохозяйственном производстве, компенсирующих рост трудозатрат в результате снижения плодородия земли. В этом случае условие равновесия можно записать как:

$$
d \frac{K_{1}}{Y_{1}}=\frac{\left(y_{1} p_{1}+y_{3} p_{3}\right)}{a p_{2}} \frac{1}{f^{\prime}\left(N_{1}\right)}
$$


Или после интегрирования:

$\frac{K_{1}}{Y_{1}}=\frac{K_{1}}{Y_{1}(0)}-\frac{\left(y_{1} p_{1}+y_{3} p_{3}\right)}{a p_{2}} \frac{N_{1}}{Y_{1}}$

где $\mathrm{K}_{1} / \mathrm{Y}_{1(0)}$ - условное значение капиталоемкости сельскохозяйственного производства, соответствующее нулевому уровню трудоемкости при данном значении уровня цен сельскохозяйственной продукции

$$
\left(\frac{\mathrm{K}_{1}}{\mathrm{Y}_{1(0)}}=\frac{\mathrm{p}_{1}}{\mathrm{ap}_{2}\left(1+\mathrm{p}^{\prime}\right)}\right)
$$

3) Снижение стоимости капитальных товаров, компенсирующее повышение стоимости труда в результате удорожания сельскохозяйственной продукции. В этом случае условие долгосрочного равновесия можно выразить как:

$$
\mathrm{dp}_{2}=\frac{\left(\mathrm{y}_{1} \mathrm{p}_{1}+\mathrm{y}_{3} \mathrm{p}_{3}\right) \mathrm{Y}_{1}}{\mathrm{aK}_{2}} \frac{1}{\mathrm{f}\left(\mathrm{N}_{1}\right)}
$$

Или после интегрирования:

$$
\mathrm{p}_{2}=\mathrm{p}_{2}(0)-\frac{\left(\mathrm{y}_{1} \mathrm{p}_{1}+\mathrm{y}_{3} \mathrm{p}_{3}\right) \mathrm{Y}_{1}}{\mathrm{aK}_{2}} \frac{\mathrm{N}_{1}}{\mathrm{Y}_{1}}
$$

где $\mathrm{p}_{2}(0)$ - условная цена капитального имущества соответствующая нулевым затратам труда при данном уровне цен на сельскохозяйственную продукцию

$$
\left(p_{2}(0)=\frac{p_{1} Y_{1}}{a K_{1}\left(1+p^{\prime}\right)}\right)
$$

4) Снижение стоимости промышленных товаров, входящих в потребление наемных работников, компенсирующее рост стоимости продовольствия. В этом случае цена предметов потребления, входящих в структуру потребления наемных работников, должна снижаться таким образом, чтобы компенсировать повышение уровня цен сельскохозяйственной продукции и сохранить неизменной величину денежной заработной платы. Это условие может быть записано как:

$$
\mathrm{dp}_{3}=-\frac{\mathrm{y}_{1}}{\mathrm{y}_{3}} \mathrm{dp}_{1}
$$

Или после интегрирования:

$$
\mathrm{p}_{3}=\mathrm{p}_{3}(0)-\frac{\mathrm{y}_{1}}{\mathrm{y}_{3}} \mathrm{p}_{1}
$$

где $\mathrm{p}_{3}(0)-$ условное значение цены предметов потребления, соответствующее нулевому значению цены на сельскохозяйственную про- дукцию при заданной величине номинальной заработной платы $\left(\mathrm{p}_{3}(0)=\mathrm{w} / \mathrm{y}_{3}\right)$.

Итак, в модели Д. Рикардо возможно четыре варианта установления долгосрочного равновесия. Однако, все они, за исключением первого, являются ограниченными. Ведь если убывание естественного плодородия не компенсируется совершенствованием техники земледелия, то компенсация его за счет снижения капиталоемкости сельскохозяйственного производства, а также за счет удешевления капитальных товаров и предметов потребления, используемых наемными работниками, может носить лишь временный характер [9]. Ведь снижение этих величин не может продолжаться бесконечно. К тому же не существует никакого объективного механизма, который связывает снижение этих величин со снижением плодородия земли. Эти тенденции абсолютно автономны и могут согласовываться лишь в результате случайного совпадения. Поэтому идея долгосрочного равновесия в теории Д.Рикардо может носить лишь негативный характер, то есть демонстрировать недостижимость этого состояния для реальной рыночной экономики. Поэтому единственным надежным средством, сдерживающим процесс убывания плодородия земли и снижения средней нормы прибыли, является ограничение роста населения, являющегося главным источником повышения спроса на продовольствие, толкающего экономику на путь истощения земельных ресурсов. В этом вопросе, Д.Рикардо солидаризируется с Т.Р.Мальтусом, также полагавшим, что рост населения является одним из главных препятствий на пути развития рыночной экономики [10]. Однако, Д.Рикардо, в отличие от T.P.Мальтуса, делает главный акцент не на темпах роста населения, а на проблеме убывания плодородия земли. Ведь если снижение плодородия земли не компенсируется противодействующими факторами, то любой, даже самый умеренный рост населения, будет вызывать тенденцию к понижению средней нормы прибыли. Поэтому достижение долгосрочного равновесия между капиталистической экономикой и природной средой для Д.Рикардо представлялось невозможным. Принципиально иной взгляд на проблему соотношения роста населения и изменения плодородия земли высказал один из позднейших представителей классической политэкономии - Г. Джордж. Он полагал, что рост населения вызывает расширение рынка и углу- 
бление разделения труда, что само по себе ведет к повышению производительности труда в земледелии и способно компенсировать тенденцию к убыванию плодородия земли и автоматически поддерживать равновесие капиталистической системы и природной среды. Он утверждал, что поскольку «...рост народонаселения, давая возможность делать большие сбережения, увеличивает производительность труда, то причина, заставляющая обращаться последовательно к земле все худшего и худшего качества, в то же самое время будет увеличивать и то количество богатства, которое эта земля может принести при затрате данного количества труда... Если эти отношения будут таковы, что увеличивающаяся производительность труда как раз будет компенсировать меньшую производительность тех земель, к которым пришлось бы обратиться, то рост народонаселения приведет к повышению ренты, включая в границу культуры худшие земли и не уменьшая заработной платы в смысле известного количества, и приведет в среднем к увеличению производства» [2].

Таким образом, описание «рикардианского эффекта» было дополнено «антирикардианским эффектом» уже в рамках классической политической экономии. Д. Рикардо и Г.Джордж предложили два альтернативных сценария взаимо- действия, лидирующего и отстающего секторов в условиях быстрой технологической трансформации. Сценарий Д.Рикардо предполагает конфликт между секторами и относительную институциональную слабость технологически передового сектора, что ведет его к стагнации и общему торможению процессов технологического преобразования. Сценарий Г. Джорджа предполагает симбиотическое взаимодействие секторов, достигающееся за счет диффузии инноваций между ними. В этом коренное отличие его подхода от подхода Д.Рикардо, который не видит возможности свободной диффузии инноваций между промышленным и агарным сектором экономики. Это является ключевым моментом не только для периода ранней индустриальной революции, но для любого процесса радикальной технологической трансформации. Именно способность лидирующего технологического сектора распространять свои инновации на другие сектора экономики и содействовать достаточно быстрому повышению их эффективности, способна устранить угрозу реализации сценария, описываемого теорией Д.Рикардо. Этот вывод является актуальным и для технологических трансформаций, переживаемых современной рыночной экономикой.

\section{Библиографический список}

1. Блауг М. Экономическая мысль в ретроспективе. М.: Дело ЛТД., 1994.

2. Джордж Г. Прогресс и бедность.-СПб, 1896.

3. Курц Х. Д. Капитал, распределение, эффективный спрос.- М., 1998.

4. Негиши Т. История экономической теории.-М., 1995.

5. Рикардо Д. Начала политической экономии и налогового обложения. Сочинения. Т. 1.- М., 1955.

6. Розанваллон П. Утопический капитализм. М.: Новое литературное обозрение, 2007.

7. Сраффа П. Производство товаров посредством товаров. Прелюдия к критике политической экономии.- М., 1999.

8. Шумпетер Й. История экономического анализа. Т. 2. СПб.: «Экономическая школа», 2001.

9. Kenwood A.G., Lougheed A. L. The Growth of international economy 1820-2000. London, 2002.

10. Malthus T.R. Principles of Political Economy - London, 1836.

11. Okishio N. Technical Change and the Rate of Profit // Kobe University Economic Review. 1961. Vol. 7. P. 85-99. 